\title{
O uso das novas mídias sociais na pesquisa de opinião pública
}

The use of new social media in public opinion research

El uso de nuevas redes sociales en la investigación de la opinión pública

\section{Leandro Leonardo Batista}

- Livre-docente pela Escola de Comunicações e Artes da Universidade de São Paulo (ECA-USP).

- Doutor em Comunicação Social pela Ủniversity of North Carolina.

- Mestre em Propaganda pela University of North Carolina.

- Graduado em Educação Física pela USP.

- $\quad$ Professor RDIDP da ÉCA-USP e do programa de pós-graduação da USP.

- E-mail: leleba@usp.br 


\section{Resumo}

Este trabalho discute a relação entre as mídias sociais e os estudos de opinião pública tendo como base uma seletiva revisão da literatura. Apresenta uma série de métodos utilizados internacionalmente para a mensuração da opinião pública pelas mídias sociais em diversas temáticas, discutindo suas vantagens e limitações, bem como as diferentes conclusões que estes métodos permitem. Tomando como foco a unidade de análise e as limitações de inferência populacional destas novas mídias, o trabalho oferece uma oportunidade de discussão acadêmica entre dados coletados via amostras populacionais de indivíduos e amostras populacionais das informações que estão exercendo influência na opinião destes indivíduos.

\section{PALAVRAS-CHAVE: OPINIÃO PÚBLICA • MÍDIAS SOCIAIS • MÉTODOS DE PESQUISA・AMOSTRAGEM.}

\section{Abstract}

Our study discusses the relationship between social media and public opinion studies based on a selective literature review. It presents a series of methods used internationally to measure public opinion in social media on various topics, discussing their advantages and limitations, and the different conclusions that these methods allow. By focusing on the unit of analysis and the limitations of population inference of these new media, our article offers an opportunity for an academic discussion involving both data collected via population samples of individuals and population samples of information that influence the opinion of these individuals.

\section{KEYWORDS: PUBLIC OPINION • SOCIAL MEDIA・RESEARCH METHODS • SAMPLING}

\section{Resumen}

Este artículo analiza la relación entre las redes sociales y los estudios de opinión pública con base en una selectiva revisión de la literatura. Presenta una serie de métodos utilizados internacionalmente para medir la opinión pública por las redes sociales sobre diversos temas, discutiendo sus ventajas y limitaciones, así como las diferentes conclusiones que permiten estos métodos. Centrándose en la unidad de análisis y las limitaciones de la inferencia poblacional de estos nuevos medios, el trabajo ofrece una oportunidad para la discusión académica entre los datos recopilados de muestras de población de individuos y muestras de población de información que están influyendo en la opinión de estas personas. 
$\mathrm{E}$ $m$ artigo recente na revista Organicom (BATISTA; PEREZ, 2016) observou-se uma discussão a respeito do impacto das novas tecnologias e de suas linguagens nos métodos e técnicas de pesquisa de mercado. Aquele artigo salienta a preocupação da área com o limite de cobertura da população que estes meios apresentavam (e ainda apresentam), mas, ao mesmo tempo, realça que alguns aspectos das novas tecnologias de fato melhoram a qualidade do dado de opinião sendo coletado.

No rápido espaço de tempo entre a publicação daquele artigo e os dias atuais, esta discussão migrou para o foco de como coletar opinião pública a partir de informações já disponíveis nas diversas mídias sociais. Nesta visão, as novas tecnologias deixam de lado seu papel de coadjuvante e passam a ser protagonistas em alguns estudos de opinião pública.

A Associação Americana de Pesquisa em Opinião Pública (Aapor em inglês) vem se preocupando com isso faz algum tempo, e já publicou os resultados de uma força tarefa de seus membros para estudar a respeito da utilização das tecnologias emergentes de comunicação nas pesquisas de opinião pública (MURPHY etal., 2014).Neste relatório os autores argumentam que estamos em uma nova era da pesquisa de opinião pública, na qual o dominante papel dos questionários (principalmente nos EUA) poderia estar chegando ao fim, uma vez que os aparelhos móveis e as plataformas de mídias sociais oferecem novas perspectivas de acesso ao pensamento da sociedade, que agora é mais dinâmico e oferecido publicamente, permitindo novas formas de coleta e análise de dados. Pessoas emitem o tempo todo opiniões a respeito dos mais diversos assuntos, uma tendência que aparentemente tende a continuar por um longo tempo, criam debates que muitas vezes simulam discussões em grupo, oferecem símbolos, significados e suas associações, assim como deixam claro suas preferências e rejeições, entre outras coisas.

Essa miríade informacional despertou o interesse de pesquisadores dos mais diversos campos, como observado pelos desenvolvimentos dos métodos de inteligência artificial, pelo uso de robôs em análise de dados, entre outros desenvolvimentos. Como afirmam $\mathrm{Ng}$, Yang e Vishwanath (2018), com a chegada da Internet e das mídias sociais, as mídias tradicionais foram superadas como fonte de informações, que agora são buscadas e trocadas por esses novos meios, de forma que, segundo esses autores, essas mídias se tornaram formadoras das percepções individuais, tendo maior durabilidade e consistência do que as informações face a face ou as originadas daquelas mídias tradicionais. Mais ainda, segundo Seltzer etal (2017), que usou 0 Instagram como meio a ser observado, as imagens coletadas e analisadas forneceram informações úteis para entender os medos e outros aspectos da opinião pública, facilitando o controle, educação e intervenções em situações especiais como nas epidemias, no caso do trabalho destes autores, do Zika vírus. Podemos então acreditar que ao mesmo tempo em que disponibilizam crenças e valores individuais e sociais, as relações sociais por estas mídias exercem uma influência sobre a saliência e a valência destas crenças e valores, portanto um efeito de agendamento e formação de atitudes (BATISTA; OZAWA, 2019). Neubaum e Krämer (2017) identificaram que os comentários contidos no Facebook influenciam a opinião dos usuários e sua vontade de participar nas discussões presentes nas mídias sociais.

Um ponto importante nesta discussão é que enquanto as mídias sociais oferecem a possibilidade de observações contínuas ao longo do tempo, diferente de surveys que, exceto em painéis, são um corte transversal e representam um momento, por outro lado, por ser um ambiente eminentemente público, limita o tipo de informação que o indivíduo decide publicar e as opiniões "politicamente corretas" podem predominar em fóruns mais inclusivos, socialmente falando, o que pode ser reduzido em entrevistas individuais, principalmente pela percepção de privacidade. Outro ponto interessante que separa estes dois métodos é a unidade de análise, enquanto em surveys em geral a unidade de análise é o indivíduo, nas mídias sociais as análises de textos e conteúdos imagéticos prevalecem, portanto, a unidade de análise passa a ser a postagem. 
As dificuldades de medir e avaliar a opinião pública não foram amenizadas com a utilização das mídias sociais, mas percebese uma ampliação dos métodos e capacidades de mensuração.

\section{MÉTODOS APLICADOS NA ANÁLISE DOS DADOS DE MÍDIAS SOCIAIS}

As formas de obtenção dos dados destas mídias vão desde as formas mais rudimentares, como copiar e colar ou simplesmente fazer cópia da tela, até formas mais automáticas em geral, utilizando a chamada Application Programming Interface (API), uma forma de acesso aos dados por linguagem de programação que varia em alcance e custo, dependendo da época e da plataforma escolhida. Por exemplo, recentemente o Twitter divulgou uma nova versão de seu API com diferentes níveis de acesso e diferenciando tipo de uso entre indivíduos, empresas e acadêmico'. Esta instabilidade de regras de acesso pode representar grandes dificuldades para pesquisadores, limitando um dos aspectos mais importantes destes meios que é, como comentado acima, a sua capacidade longitudinal de coleta de dados.

Uma vez coletado o dado, a metodologia de análise mais comum é a análise de textos e imagens de postagens individuais, a qual nos oferece um grande leque de técnicas e softwares, tais como NVivo e Iramuteq que combinam análises qualitativas e quantitativas de linguagem natural, gerando formas de visualizar dados com grande capacidade exploratória e inferencial de informação potencialmente relevante. No entanto estas formas técnicas devem ser usadas com cautela pela sua baixa capacidade de identificar sutilezas de linguagens e/ou de imagens.

A combinação de buscas específicas desenhadas pelo pesquisador com as potencialidades automáticas destes (e outros) softwares neste conjunto de dados podem gerar resultados bastante específicos. Um alerta sobre isto aparece no relatório da força tarefa da AAPOR (MURPHY etal., 2014, p.22), salientando que os esforços de seleção e agrupamento destes dados devem se preocupar com dois fatores: precisão e alcance (precision e recall ${ }^{2}$ no original), sendo que o primeiro é avaliado pela capacidade de identificação do termo de busca, ou seja, avalia a proporção de postagens selecionadas pela busca e que estão relacionadas com o objetivo da pesquisa; e o segundo pela especificidade da busca, quando a especificidade é baixa a proporção de postagens coletadas em relação ao total de postagens é alta, quanto mais específica esta busca menor a quantidade de postagens selecionadas. Em geral alguma interferência humana é necessária nestas buscas, pois ironias e outras formas de linguagem podem gerar dados que não fazem parte da intenção do pesquisador, quanto maior esta interferência menor é a precisão.

Mazer etal. (2015) usaram uma combinação de análise manual e automatizada para avaliar conversas sobre dois tiroteios urbanos nos EUA coletadas no Facebook, Twitter, blogs e websites de mídias tradicionais e notaram que o volume de informações nas mídias sociais era muito maior do que nas mídias tradicionais. As autoras, então, as classificaram como muito mais informacionais do que emocionais. Mais de 5.000 postagens foram coletadas por estes autores durante a primeira semana após os incidentes e, entre outros pontos, notaram que os segmentos de pais e de estudantes focavam em aspectos diferentes do incidente, mostrando a capacidade da mídia em identificar segmentos da população com diferentes perspectivas, um ponto importante para entender a opinião pública e estabelecer linhas de comunicação com a sociedade.

Mais recentemente, um evento parecido com os estudados por Mazer etal. (2015), mas envolvendo um grande número de mortes - 14 estudantes e 3 funcionários de uma escola em Portland, EUA - foi estudado por Austin, Guidry e Meyer (2020) que usaram as hashtags \#parkland, \#parklandshooting, ou \#neveragain para coletar uma amostra randômica de 500 postagens

'Disponível em: https://macmagazine.uol.com.br/post/2020/08/12/twitter-lanca-nova-versao-da-sua-api-com-boas-novidades-para-desenvolvedores/. Acesso em: 12 ago. 2020.

${ }^{2}$ Embora alcance possa não ser uma boa tradução de recall, a escolha por este termo visa facilitar o entendimento. 
do Instagram e do Twitter (1.000 no total) e, através de uma análise quantitativa de conteúdo, considerando indicadores de teorias de percepção do risco, características de engajamento, enquadramento e discussões a respeito de violência e armas, encontraram que as duas plataformas tinham bases diferentes para esta discussão, enquanto campanhas pelo desarmamento e percepção de risco estavam mais presentes no Instagram, por outro lado, as postagens no Twitter eram mais centradas em aspectos associados às políticas públicas de prevenção da violência. Engajamento foi identificado nas duas plataformas, mas raiva estava mais associada ao engajamento no Instagram, o que, conforme as autoras pode ser um efeito associado ao conteúdo desta plataforma que privilegia imagens e estas, nestes eventos, podem ser emocionalmente mais agressivas.

Um ponto bastante relevante a ser observado nos estudos de mídias sociais é a fonte da postagem, que pode tanto ser um indivíduo, uma organização e principalmente robôs. Um estudo (MARTINEZ etal., 2018) que observou a fonte, o contexto e as características de 973 mensagens selecionadas randomicamente de 193.051 tweets entre 2015 e 2016 (portanto, um estudo longitudinal) sobre os e-cigarretes, e que foram manualmente codificados, separa os resultados entre organizações e indivíduos, sendo que os últimos têm uma presença duas vezes maior que as primeiras, no entanto, mais da metade destas postagens individuais são potencialmente robôs, com a remoção destas fontes a participação de mensagens oriundas de indivíduos cai de $91,2 \%$ para $74,5 \%$, o que reduz a presença de indivíduos na amostra, mas não afetou a proporção de sentimentos positivos e negativos, sendo que as organizações apresentam uma tendência maior de postagens positivas do que indivíduos. Apesar de que os assuntos mais presentes nestas postagens tenham sido os estigmas e malefícios associados ao cigarro eletrônico, um ponto salientado pelos autores é que nenhuma postagem fazia referência negativa aos efeitos respiratórios associados ao uso deste produto, fato bastante explorado mais recentemente ${ }^{3}$.

Outro aspecto importante nos estudos de opinião pública atrelados ao uso das mídias sociais que pode ser observado é a localização geográfica. Em um estudo que explora este aspecto a partir das redes sociais, Gong etal. (2020) usam dados de localização geográfica para estudar tweets da eleição presidencial em 2016 nos EUA, podendo, com isso, construir uma visualização espacial que estabelece uma relação entre local geográfico e opiniões e as predições de resultados eleitorais. Embora o método seja o ponto alto deste trabalho, ao mesmo tempo é a parte mais difícil da publicação, mas deixa claro que os dados geográficos adicionados à análise das postagens geram importantes informações a respeito do que se quer observar.

Ainda dentro desta consideração geográfica e considerações políticas, Lopez-Lopez, Onate e Rocha (2020) analisaram as reações no Twitter em eleições presidenciais na Argentina, Peru, Equador, Honduras, e Chile entre 2015 e 2017. Observaram 200.000 tweets identificando que as emoções observadas nestas comunicações tinham uma grande correlação com os resultados das eleições naqueles países. As postagens poderiam ser separadas por correntes ideológicas com emoções positivas prevalecendo em relação aos candidatos considerados à direita politicamente, por outro lado candidatos considerados mais progressistas estavam mais associados a conteúdos classificados como contendo raiva e tristeza do que os candidatos mais conservadores. A consideração das relações destes estudos indica o potencial da inclusão da análise geográfica nos estudos de opinião pública através das mídias sociais, seja para salientar as diferenças como em Gong etal. (2020) ou as similaridades como em Lopez-Lopez etal. (2020).

Vieira e Seleghim (2020) também fizeram uso das mídias sociais como um termômetro do processo de tomada de decisão do governo brasileiro com base em análise de sentimentos, uma técnica bastante presente em estudos de mídias, a qual consiste em classificar os sentimentos da opinião pública manifestados nos textos postados na rede social escolhida em positivo, neutro ou negativo. Os autores identificaram que a atenção do governo a determinados assuntos está associada à polarização no meio social. Este estudo determinou como unidade de análise os decretos presidenciais durante janeiro e

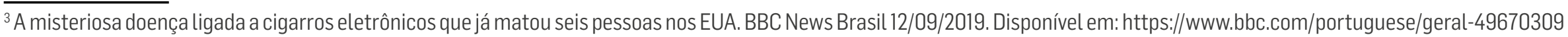


junho de 2019 (uma análise longitudinal). Usando hashtags específicas e associadas aos decretos presidenciais, identificaram 750 tweets que foram categorizados manualmente e, com isso, puderam identificar o papel de termômetro que as mídias sociais vêm representando para as decisões governamentais no Brasil recentemente.

Dentro desta ideia de termômetro ou o uso das mídias sociais para avaliar e encontrar pontos de contato com a sociedade, Jiang etal. (2019) usaram conteúdo de mídia social para identificar os temas que podem representar vantagens para promover o conhecimento e atitudes da população em relação à doação de órgãos. A partir de uma base de 16 milhões de usuários, extraíram 1507 repostas dadas a 141 postagens, avaliadas em função das respostas e comentários recebidos. Com base nesta metodologia, identificaram dois temas que influenciavam o conhecimento do problema social: estatísticas sobre doação de órgãos e a significância da doação; estes dois temas associados com a significância da doação para a sociedade eram os mais efetivos em aumentar suporte para a causa e intenção de ser um doador.

Esta pesquisa está associada a trabalho publicado recentemente sobre o papel do governo em situações de emergência, Teichmann etal. (2020) salientam que comunicação oficial de saúde deve se preocupar com efeitos distintos considerando as mídias sociais, devido às características do meio e às preferências dos usuários, além dos algoritmos específicos de cada mídia. Os autores salientam que em geral quem posta é mais relevante do que se posta, líderes têm capacidade de gerar mais interesse em compartilhar mensagens do que não líderes. Mensagens concisas, simples e diretamente solicitando algum tipo de comportamento são estrategicamente mais efetivas, portanto, informações detalhadas não são boas práticas para essas funções governamentais. Outra consideração observada nesta pesquisa é que, em geral, governos postam mensagens idênticas ou quase idênticas em diferentes mídias, uma prática que não é muito produtiva, pois estes autores observaram que o Facebook gera mais engajamento nas problemáticas locais, enquanto o Twitter é mais efetivo em problemáticas gerais; além disso, nesta última plataforma, o vídeo é mais efetivo e mensagens concisas no Facebook têm uma durabilidade maior.

Através desta seletiva revisão da literatura podemos observar que não só os dados são abundantes como também o são as possibilidades de observá-los metodologicamente. Assim, a preocupação com a qualidade do dado pelas considerações de disponibilidade (ex. API), precisão e alcance, sua distribuição geográfica e as especificidades do meio são importantes passos iniciais na preparação de um estudo de opinião pública pelas mídias sociais. Nota-se nestes estudos que não só palavraschave e as hashtags foram utilizados como buscadores para identificar e selecionar as postagens a serem analisadas, mas o número de respostas recebidas também foi o indicador, como em Jiang etal. (2019).

A codificação destes dados, seja ela manual ou automática, deve partir da escolha pela unidade de análise que pode ser definida pela importância social como fizeram Vieira e Seleghim (2020) que usaram os decretos presidenciais, ou por importância acadêmica, como fizeram Austin, Guidry e Meyer (2020), que definiram os códigos para a análise de conteúdo seguindo definições acadêmicas de teorias de percepção do risco, características de engajamento, enquadramento (framing) e discussões acadêmicas a respeito de violência e armas.

A combinação de mais de uma plataforma é bastante presente nestes estudos, mas algumas prevalecem pela acessibilidade e/ou dinâmica de interação entre os usuários, como por exemplo o Twitter. Em geral as plataformas combinadas em um único estudo trazem pontos diferentes, seja pelas emoções causadas, como em Austin, Guidry e Meyer (2020), seja pela finalidade da comunicação, como demonstraram Teichmann etal. (2020) no estudo de comunicação governamental.

Outro ponto que merece bastante atenção, principalmente em estudos que envolvam o Twitter, é a presença de robôs que, como demonstrado por Martinez etal. (2018), pode representar uma considerável porção do que é obtido nestas coletas, embora esta remoção seja tecnicamente avançada ela é muito importante para entender a segmentação dos dados. Esta segmentação, seja por tipo de usuário, geográfica ou comportamental, pode ser um ponto muito relevante nesta área de estudos. 


\section{VIESES}

Hargittai (2020), uma pesquisadora importante destes vieses, levanta algumas preocupações em relação a este tipo de pesquisa tendo em vista que pessoas com nível econômico mais elevado tendem a estar presentes em muitas plataformas ao mesmo tempo, assim este grupo tende a ser super representado nestes estudos; por outro lado as habilidades com o uso de Internet e mídias sociais em geral não estão difundidas igualmente em todos os estratos sociais, mais jovens tendem a ter mais desta capacidade e podem, desta maneira, também estar representados acima do que seu estrato deveria estar em uma amostra mais representativa da população. Assim, os menos privilegiados financeiramente e/ou tecnologicamente tendem a ser subrepresentados nesses tipos de estudo, desta forma as opiniões coletadas por estes métodos devem ser sempre consideradas em relação a este viés inerente destas mídias, principalmente quando se busca uma representatividade populacional.

Os vieses presentes nestes estudos (ver Hargittai, 2007, 2020; Blank; Lutz, 2017), quando considerados em seu aspecto representativo da população, indicam que as plataformas de mídias sociais não são representativas das distribuições populacionais. Seja no uso ou na adoção destas novas tecnologias, estes estudos mostram que esta talvez seja a maior preocupação quando da inferência dos dados coletados como representando uma população, ainda que o volume de dados gere uma expectativa de tendência aos pontos convergentes da opinião pública o viés demográfico é um alerta que não pode ser ignorado. Segundo os estudiosos destes vieses, a pouca representatividade pode ser estendida até para a representatividade dos usuários entre plataformas, por exemplo Duggan etal. (2015) encontraram que em 20140 uso da plataforma Pinterest nos EUA era dominado pelas mulheres e que uma grande parte (42\%) das mulheres on-line usavam esta plataforma, enquanto somente $13 \%$ dos homens o faziam.

Estes efeitos entre plataformas podem afetar até recrutamento de participantes feitos por estes meios, uma vez que um sistema cada vez mais comum de encontrar participantes voluntários ou não para estudos sociais, clínicos e/ou acadêmicos é colocar anúncios solicitando participantes. Em um destes estudos (STERN etal., 2017) observaram que os recrutados pelo Facebook eram diferentes demograficamente dos recrutados por anúncios no Google, os primeiros eram em sua maioria brancos, com educação e renda maiores do que os recrutados pelo Google. Desta forma, temos que não só a distribuição populacional é diferente entre as plataformas, mas também é possível esperar que comportamentos sejam afetados pelo ambiente da plataforma. Como discutido acima, mídias que privilegiam imagens podem afetar diferentemente daquelas onde textos dominam.

\section{CONSIDERAÇÕES FINAIS}

As mídias sociais nos oferecem um cenário inovador nas pesquisas de opinião pública, área que vem evoluindo tão rapidamente quanto os meios de comunicação nesta era eletrônica. Se por um lado a qualidade e agilidade de coleta de dados pelos meios tradicionais de entrevista pessoal ganharam uma série de técnicas auxiliares, estes mesmos avanços trouxeram vieses que limitam a inferência de dados; foi assim desde a introdução das pesquisas por telefone que deixavam uma parcela da população excluída do processo de mensuração da opinião pública, até com a introdução do celular na sociedade que eliminou quase que por completo os telefones residenciais, limitando os desenhos amostrais por geolocalização que os telefones fixos ofereciam.

A relação discutida acima entre o potencial de análise oferecido pela chamada big datae os vieses inerentes destes dados nos dirigem para uma nova época da análise de opinião pública que pode ser menos representativa do ponto de vista populacional, mas muito mais dinâmica e informativa pela facilidade de coletar uma opinião disponibilizada voluntária e continuamente de 
forma espontânea, ou provocada por outros participantes ou por eventos como decretos presidenciais, doenças contagiosas ou movimentos políticos.

O ponto importante desta discussão passa pela transição da unidade de análise focada em indivíduos, como em questionários de opinião pública, para a informação disponibilizada tanto por meios tradicionais como pelos próprios participantes destas plataformas. Embora estas informações não representem a população demograficamente, elas representam as fontes de informação, são úteis para entender o que aflige uma população ou o que a estimula a participar em problemas sociais como doação de órgãos, ou ainda como as suas crenças e valores estão distribuídas nas suas relações sociais e assim observar como estas informações estão exercendo influência sobre a saliência e valência de temas importantes para uma sociedade.

\section{REFERÊNCIAS}

BATISTA, Leandro Leonardo; PEREZ, Clotilde. Novos meios e novos métodos de pesquisa: desafios, soluções e avanços. Organicom, São Paulo, v.13, n.25, p.69-78, 2016.

BLANK, Grant; LUTZ, Christoph. Representativeness of social media in Great Britain: investigating Facebook, Linkedin, Twitter, Pinterest, Google+, and Instagram. American Behavioral Scientist, Thousand Oaks, v.61, n.7, p.741-756, 2017.

DUGGAN, Maeve etal. Social media update 2014. Pew Research Center, Washington, DC, v.19, p.1-2, 2015.

GONG, Zhaoya etal. Measuring relative opinion from location-based social media: A case study of the 2016 US presidential election. Plos one, Beijing, v. 15, n. 5, e0233660, 2020.

GUIDRY, Jeanine PD; AUSTIN, Lucinda; MEYER, Michele. \#Gunviolence on instagram and twitter: examining social media in the wake of the parkland school shooting. Journals of Public Interest Communications, Gainesville, v.4, n.1, p.4-36, 2020.

HARGITTAI, Eszter. Potential biases in big data: omitted voices on social media. Social Science Computer Review, Thousand Oaks, v.38, n.1, p.10-24, 2020.

HARGITTAI, Eszter. Whose space? Differences among users and non-users of social network sites. Journal of ComputerMediated Communication, Hoboken, v.13, n.1, p.276-297, 2007.

JIANG, Xiaoya etal. Characterizing media content and effects of organ donation on a social media platform: content analysis. Journal of Medical Internet Research, Toronto, v.21, n.3, e13058, 2019

LOPEZ-LOPEZ, Paulo Carlos; ONATE, Pablo; ROCHA, Alvaro. Social media mining, debate and feelings: digital public opinion's reaction in five presidential elections in Latin America. Cluster Computing, New York, p.1-12, 2020.

MAZER, Joseph P.; THOMPSON, Blair; CHERRY, Jessica; RUSSELL, Mattie; PAYNE, Holly J.; KIRBY, E. Gail; PFOHL, William. Communication in the face of a school crisis: examining the volume and content of social media mentions during active shooter incidents. Computers in Human Behavior,Amsterdam, v.53, p.238-248, 2015.

MURPHY, Joe etal. Social media in public opinion research: executive summary of the aapor task force on emerging technologies in public opinion research. Public Opinion Quarterly, Oxford, v.78, n. 4, p.788-794, 2014. 
NEUBAUM, German; KRÄMER, Nicole C. Monitoring the opinion of the crowd: psychological mechanisms underlying public opinion perceptions on social media. Media Psychology, Abingdon, v.20, n.3, p.502-531, 2017.

NG, Yu Jie; YANG, Janet; VISHWANATH, Arun. To fear or not to fear? Applying the social amplification of risk framework on two environmental health risks in Singapore. Journal of Risk Research, Abingdon, v.21, n.12, p.1487-1501, 2018.

OZAWA, João Vicente Seno e BATISTA, Leandro Leonardo. A análise de redes sociais como uma proposta metodológica para estudos da teoria da agenda-setting. In: SEMINÁRIO INTERNACIONAL DE PESQUISAS EM MIDIATIZAÇÃO E PROCESSOS SOCIAIS, 3., 2019, São Leopoldo. Anais [...]. São Leopoldo: Unisinos, 2019. p.1-15.

SELTZER, Emily etal. Public sentiment and discourse about Zika virus on Instagram. Public Health, Bethesda, v.150, p.170-175, 2017.

TEICHMANN, Lisa etal. Public health communication and engagement on social media during the Covid-19 pandemic. Osf.io, 2020. doi: 10.31219/osf.io/7hypj.

VIEIRA, Aiane de 0.; SELEGHIM, Ariane D. Populismo, governabilidade e opinião pública: uma análise da influência das mídias digitais no processo decisório presidencial. Agenda Política, São Carlos, v.8, n.2, p.163-186, 2020.

Artigo recebido em 15.8.2020 e aprovado em 8.1.2021 